\title{
Clinical Significance of In-Hospital Reocclusion After Mechanical Reperfusion and Percutaneous Transluminal Coronary Angioplasty for Acute Myocardial Infarction
}

\author{
Eva Cantalejo M unhoz, Paulo Franco de O liveira \\ Curitiba, PR - Brazil
}

\begin{abstract}
Objective - To analyze the effects of in-hospital reocclusion of reperfused AMI culprit coronary arteries in mortality and to identify the predictors.

Methods - The present study comprises a sample of 155 patients with AMI who underwent successful mechanical reperfusion by direct coronary angioplasty and angiographic control during hospitalization or before discharge. Patients were classified into group A: reoccluded patients $(n=30)$ and group B: non-reoccluded patients $(n=125)$.
\end{abstract}

Results - We identified in-hospital reocclusion predictors and found a greater significance in mortality among reoccluded patients $(23,3 \% \times 1.6 \% ; p=0.00004)$. Silent reocclusion or typical angina at reocclusion had a good prognosis. The independent predictors of in-hospital mortality were hypertension, multiarterial lesions, totally occluded AMI culprit lesions, failed redilatation, failed redilatation in comparison with no intention to redilate, no redilatation in comparison with no atempt to redilate, and reocclusion within the first 48 to 72 hours. The decision to redilate, independently of the result, led to a $50.0 \%$ reduction in hospital mortality $(p=0.0366)$.

Conclusion - In-hospital AMI culprit coronary artery reocclusion had an adverse effect-similar to that reported in clinical studies with high mortality rates $(23.3 \% x$ $1.6 \% ; p=0.00004$ ). The major contribution of this study is to recommend the reopening of reoccluded AMI culprit coronary arteries as a means for the management of coronary artery reocclusion.

Keywords: acute myocardial infarction, coronary reocclusion, reinfarction

Irmandade da Santa Casa de Misericórdia de Curitiba

Mailing address: Eva Cantalejo Munhoz Stadler de Souza - Rua Visconde do Rio Branco, 1335 - S/93-94 e 101 - 80420-210 - Curitiba, PR - Brazil - E-mail: stadler@crt.sol.com.br
Reinfarction, or acute myocardial infarction (AMI) extension, has been reported in many clinical studies as a lethal complication in the outcome of AMI ${ }^{1-7}$ with diagnosis criteria based on clinical data, myocardial enzymes ${ }^{1,5}, \mathrm{EKG}^{8,9}$, and also by angiographic data. Reinfarction can occur without an angiographic registry of the total occlusion of the culprit AMI artery ${ }^{10-13}$. The incidence was reported between 8.0 and $30.0 \%$ in non-reperfused patients, $17.0 \%$ at autopsy, and 5.0 to $15.0 \%$ in reperfused patients ${ }^{5,13-17}$ and between 18.0 to $25.5 \%$ for inferior AMI, and 6.0 to $12.8 \%$ for anterior AMI ${ }^{17-21}$. It can be silent in 42.0 to $50.0 \%$ of cases ${ }^{6,22}$.

Because of the severe implications and because no studies involving the clinical significance of the in-hospital reocclusion after direct mechanical reperfusion and PTCA have been published, we studied these phenomena to better understand the effects and clinical significance of reocclusion and to the predictors, and to especially pay attention to mortality related to the reocclusion phenomenon.

\section{Methods}

Patients with a diagnosis of AMI admitted to Irmandade da Santa Casa de Misericórdia, Curitiba, Paraná, Brazil and the Instituto Modelo de Cardiologia, Cordoba, República Argentina from January 1983 to March 1993 received treatment with direct mechanical reperfusion and PTCA. Each patient had AMI confirmed by clinical, hemodynamic, and laboratory data. Patients were consecutive and included those with recovered cardiac arrest, shock, multivessel or associated left main lesions, previous CABG, previous AMI, and advanced age.

All patients were classified according to Killip-Kimbal clinical classifications ${ }^{23,24}$, but a group of patients were considered to have no-class because of cardiac arrest, complete A-V block, or shock associated with ventricular tachycardia. AMI sites were defined either by EKG, or hemodynamic patterns, or both. Every patient received nitrates, sedatives, analgesics, and 10,000 units IV of heparin, and after consent, they underwent diagnostic cardiac catheterization 
and interventional therapeutics as described in a previous study ${ }^{15,25}$. After the procedure, all patients went to the CCU for continuous monitoring of their EKG, blood pressure, and hemodynamics (temporary pacemaker or IABP in specific indications). All patients were autocoagulated with heparin ( 1000 units IV/hour) for the first 48 hours or during the entire hospital stay and received antiplatelet agents (ASA). Beta-blockers, calcium antagonists, and other drugs were selected by attending cardiologists. Reocclusion was defined as total occlusion of the culprit AMI artery that had previously been reperfused. All patients had to achieve TIMI grade flow III after PTCA, and only those who did were considered to be successful. The total population of successful PTCAs was 391 AMI patients, but only 155 had an angiogram performed prior to discharge. These 155 patients were then classified into the reocclusion group (group A) and the nonreocclusion group (group B). Clinical data on the posterior analysis were recorded with "Hemopac", an institutional software program.

Student $t$ test, the chi-square test, Fisher's exact test, the median test, and the Kruskal-Wallis test were performed for two independent samples, and the binomial test was performed for a unique sample. Multiple regression analysis and Fisher's discriminant analysis were performed with SAEG software ${ }^{26-28}$. The significance level adopted was $5.0 \%(\mathrm{p}<0.05)$.

\section{Results}

A total sample of 155 AMI patients underwent mechanical reperfusion with PTCA with initial success and a repeated angiogram before discharge. Ages ranged from 29 to 82 years $(57.5 \pm 11.4)$. After repeat cardiac catheterization, patients were classified as group $A$ (reoccluded, $n=30$ ) and as group $B$ (nonreoccluded, $n=125$ ).

Table I and II show the clinical and angiographic baseline characteristics.

Discriminant analysis applied to 155 patients allowed the identification or classification, or both of patients who previously could or could not be identified as having reocclusion (error probability $=10.6 \%$ ), the formula for strong significance being $\mathrm{F}_{\text {calc }}=60.24 ; \mathrm{F}_{\mathrm{tab}}=3.64 ; \mathrm{p}<0.001$. This model identified the following 18 variables: in-hospital mortality, clinical class, age, sex, diabetes, hypertension, smoking, family history of CAD, hyperlipidemia, obesity, number of damaged vessels, number of dilated vessels, type of vessels (single vessel or multivessel), AMI culprit artery, type of lesion, AMI site, flow grade, and reperfusion time with a total possibility of correct classification of $79.0 \%$ (60.0\% for group A and $84.0 \%$ for group B).

Although the group A mean age was higher than that of group B $(60.6 \pm 11.2 \times 56.8 \pm 11.4)$ and although when correlated with sex, female patients were older $(66.0 \pm 12.1 \mathrm{x}$ $59.6 \pm 10.9$ for group $A$ and $65.2 \pm 8.7 \times 55.2 \pm 11.2$ for group B), the univariate analysis did not show significances.

Univariate analysis demonstrated significances favorable to reocclusion (group A) for the following: female sex, hypertension, family history of $\mathrm{CAD}$, hyperlipidemia $(\mathrm{p}<0$. 005), obesity ( $\mathrm{p}<0.025)$, inferior and associationed AMI site, reperfusion time up to $240 \mathrm{~min}(\mathrm{p}<0.005)$, also up to $360 \mathrm{~min}$ $(\mathrm{p}<0.05)$, Killip I class ( $\mathrm{p}<0.005)$, no-class $(\mathrm{p}<0.025)$, and the sum of III plus IV and no-class patients ( $p<0.005)$, multives-

\begin{tabular}{|c|c|c|c|c|c|c|}
\hline \multicolumn{7}{|c|}{ Table I - Baseline clinical characteristics } \\
\hline \multirow[t]{2}{*}{ Variables } & \multicolumn{2}{|c|}{ All patients } & \multicolumn{2}{|c|}{ Reocclusion } & \multicolumn{2}{|c|}{ No reocclusion } \\
\hline & $\mathrm{n}=155$ & $\%$ & $\mathrm{n}=30$ & $\%$ & $\mathrm{n}=125$ & $\%$ \\
\hline \multicolumn{7}{|l|}{ Sex } \\
\hline - Male & 131 & 84.5 & 25 & 83.3 & 106 & 84.8 \\
\hline - Female & 24 & 15.5 & 05 & 16.7 & 19 & 15.2 \\
\hline \multicolumn{7}{|c|}{ CAD Risk Factors } \\
\hline - None & 40 & 25.8 & 07 & 23.3 & 33 & 26.4 \\
\hline - Diabetes & 16 & 10.3 & 06 & 20.0 & 10 & 8.0 \\
\hline - Hipertension & 55 & 35.5 & 11 & 36.7 & 44 & 35.2 \\
\hline - Smoking & 73 & 47.1 & 14 & 46.7 & 59 & 47.2 \\
\hline - CAD family history & y 31 & 20.0 & 07 & 23.3 & 24 & 19.2 \\
\hline - Dyslipidemia & 44 & 28.4 & 11 & 36.7 & 33 & 26.4 \\
\hline - Obesity & 40 & 25.8 & 12 & 40.0 & 28 & 22.4 \\
\hline Previous CABG & 06 & 3.9 & 01 & 3.3 & 05 & 4.0 \\
\hline Previous AMI & 17 & 11.0 & 02 & 6.7 & 15 & 12.0 \\
\hline \multicolumn{7}{|l|}{ AMI Site } \\
\hline - Anterior & 60 & 38.7 & 09 & 30.0 & 51 & 40.8 \\
\hline •Inferior & 52 & 33.6 & 12 & 40.0 & 40 & 32.0 \\
\hline - Associations & 43 & 27.7 & 09 & 30.0 & 34 & 27.2 \\
\hline \multicolumn{7}{|l|}{ Clinical class } \\
\hline - Killip I & 80 & 51.6 & 16 & 53.4 & 64 & 51.2 \\
\hline - Killip II & 35 & 22.6 & 05 & 16.7 & 30 & 24.0 \\
\hline - Killip III & 14 & 9.0 & 04 & 13.3 & 10 & 8.0 \\
\hline - Killip IV & 07 & 4.5 & 01 & 3.3 & 06 & 4.8 \\
\hline - No-Class & 19 & 12.3 & 04 & 13.3 & 15 & 12.0 \\
\hline \multicolumn{7}{|l|}{ Mortality } \\
\hline - Global & 09 & 5.8 & 07 & 23.3 & 02 & 1.6 \\
\hline - Cardiac & 08 & 5.2 & 07 & 23.3 & 01 & 0.8 \\
\hline - Non cardiac & 01 & 0.6 & - & - & 01 & 0.8 \\
\hline Hospital discharge & 146 & 94.2 & 23 & 76.7 & 123 & 98.4 \\
\hline
\end{tabular}

\begin{tabular}{|lcccccc|}
\hline \multicolumn{7}{|c}{ Table II - Baseline angiographic characteristics } \\
\hline \multicolumn{7}{|c}{ All patients } \\
\hline
\end{tabular}


sel lesions, right coronary artery as the culprit AMI artery, critical lesions on first angioplasty ( $\mathrm{p}<0.005)$, and also global mortality ( $\mathrm{p}=0.0001)$ and cardiac mortality $(\mathrm{p}=0.00004)$.

Univariate analysis permitted identification of the following variables favorable to nonreocclusion (group B): male sex; non-CAD risk factors, smoking, anterior MI, reperfusion time from 241 to 360 minutes; Killip II and the sum of Killip I plus Killip II classes; single vessel lesions, LAD culprit MI artery, and total lesion (TIMI flow 0) at first angiogram with a probability of $\mathrm{p}<0.005$ for all variables.

No significant conclusions were reached about diabetes, previous CABG, previous MI (late), damaged vessels/ patients ratio, dilated vessel/patient ratio, and circumflex culprit MI artery.

Global in-hospital mortality was $5.8 \%$, being $5.2 \%$ from cardiac causes. Group A mortality was $23.3 \%$ (all cardiac causes and group B of $1.6 \%$, with $0.8 \%$ from cardiac causes), which was considered highly significant $(\mathrm{p}=0.00004)$. Also group A mortality was 4 times the global mortality $(\mathrm{p}=0.00$ $01), 14.6$ times the group B mortality $(\mathrm{p}<0.0001)$, and 29.1 times the group B cardiac mortality ( $\mathrm{p}=0.00004)$. Group B had a reduction in mortality 3.6 times that of the global mortality $(1.6 \% \times 5.8 \%)(\mathrm{p}<0.05)$.

Of the 30 reoccluded patients, $20.0 \%$ were asymptomatic at reocclusion, and all of them survived $(\mathrm{p}<0.005)$. Of symptomatic patients, $60.0 \%$ had isolated clinical data, angina and complete $\mathrm{A}-\mathrm{V}$ blockage being the most frequent. Also those with isolated clinical data had a better prognosis $(\mathrm{p}<0.025)$, better when it was angina $(\mathrm{p}<0.01)$. Associated clinical data were found in $40.0 \%$ of symptomatic patients, and those with angina had a good prognosis $(\mathrm{p}<0.025)$ also.

Every patient who reoccluded while in shock died $(\mathrm{p}=0.0483)$. All patients whose reocclusions were suspected because of arrythmias in fact were reoccluded, and they had a higher mortality rate $(\mathrm{p}=0.0002)$.

Out of the 30 reoccluded patients, 16 reoccluded within 72 hours post-PTCA, and this accounted for $85.7 \%$ of the reoccluded in-hospital mortalities. Within 24 hours, $16.7 \%$ of patients reoccluded, and $57.1 \%$ died ( $\mathrm{p}=0.0052)$. After 72 hours post-PTCA, $46.7 \%$ of patients reoccluded and $14.3 \%$ died.

Five patients reoccluded within the first 24 hours postPTCA and 3 within the first 6 hours. All these 3 patients died (Table III). So we tested the hypothesis that earlier reocclusion means increased mortality ( $\mathrm{p}=0.0262)$.

The majority of patients were in Killip class I at reocclusion (56.7\%), but $40.0 \%$ were in Killip class III, IV, or had no data on class, and had greated mortality $(\mathrm{p}<0.005)$.

Every patient who were better clinical class at reocclusion than on admission survived, but those maintaining the same class had $15.8 \%$ mortality, and those who were in a worse class had $50.0 \%$ mortality.

At reocclusion, 25 patients (83.3\%) were redilated; $64.0 \%$ of these were successfully dilated, and 5 patients were not redilated; 2 patients went on to CABG electively because of associated lesions.

Redilated patients, despite the results, had a better prognosis $(87.0 \%$ survive $)(\mathrm{p}<0.005)$; but nonredilated patients had higher mortality rates $(28.6 \%$ x $13.0 \%)(\mathrm{p}<0.025)$, and failed redilation showed higher mortality also $(71.4 \% \mathrm{x}$ $17.4 \%)(\mathrm{p}=0.0024)$.

When the intention to redilate versus not to redilate were compared, a $50.0 \%$ reduction in mortality favorable to redilation was seen $(\mathrm{p}=0.0366)$. Also when redilated patients were compared with failure or no redilation, no significance $(\mathrm{p}=0.3671$ ) was observed.

Patients who died had a higher mean age $(70.0 \pm 8.1 \mathrm{x}$ $57.8 \pm 10.5$ years old $)(\mathrm{p}<0.01)$. Also, male patients were older $(70.0 \pm 4.3 \times 59.6 \pm 10.9$ years old $)(\mathrm{p}<0.01)$. Although female sex had a higher mortality $(42.9 \%$ x $8.7 \%)(\mathrm{p}<0.005)$, female's older age was not significant.

Of deceased patients, significances were reached for hypertension, a family history of CAD, AMI site associations ( $\mathrm{p}<0.005)$, a major number of damaged vessel $(\mathrm{p}<0.0$ 25 ), the total occlusion of the culprit AMI artery (TIMI 0 ), multivessel lesions ( $\mathrm{p}<0.005)$, and as related previously, reocclusions with shock $(\mathrm{p}<0.0483)$, reocclusion within the first 24 hours $(p<0.005)$, failed redilation $(p=0.0024)$, nonredilated ( $p<0.025)$, Killip III plus IV, and no-class at reocclusion $(\mathrm{p}<0.005)$, and no-class patients with isolated predictors $(\mathrm{p}<0.005)$.

The analysis of independent in-hospital mortality predictors showed hypertension $(\mathrm{p}=0.0366)$, dilated damaged vessels ratio $(p<0.0001)$, patients with multivessel disea$\operatorname{se}(\mathrm{p}<0.0002)$, total occlusion of the culprit AMI artery (TIMI 0$)(p=0.0366)$, failed redilation $(\mathrm{p}=0.0366)$, failed redilation when compared with not trying to redilate $(\mathrm{p}=0.0366)$, not trying to redilate compared with trying to redilate $(\mathrm{p}=0.03$ 66 ), and reocclusion time up to 48 hours ( $\mathrm{p}=0.0366)$, and greater significance up to 72 hours post-PTCA $(\mathrm{p}<0.0001)$.

At discharge, only 23 reoccluded patients existed, but $87.0 \%$ were in NYHA class I; 16 (69.6\%) with patent culprit AMI arteries, and 7 with the AMI culprit artery totally occluded by unsuccessful redilation (4 patients), or no redilation in 3 patients.

\section{Discussion}

The small number of angiographic restudies (155/391) and the fact that in all patients suspected of reocclusion a restudy was performed will not permit analysis of the reocclusion rate. Discriminant analysis demonstrated a model with a good probability of identifying or classifying the

\begin{tabular}{|c|c|c|c|c|c|c|}
\hline \multicolumn{7}{|c|}{ Table III - Reocclusion time after initial PTCA } \\
\hline \multirow{2}{*}{$\begin{array}{l}\text { Reocclusion } \\
\text { time }\end{array}$} & \multicolumn{2}{|c|}{ Dead patients } & \multicolumn{2}{|c|}{ Survivours } & \multicolumn{2}{|c|}{ All patients } \\
\hline & $\mathrm{N}$ & $\%$ & $\mathrm{n}$ & $\%$ & $\mathrm{n}$ & $\%$ \\
\hline Up to 24 hours & 4 & 57.1 & 01 & 4.4 & 05 & 16.7 \\
\hline $24-48$ hours & 1 & 14.3 & 04 & 17.4 & 05 & 16.6 \\
\hline After 72 hours & 1 & 14.3 & 05 & 21.7 & 06 & 20.0 \\
\hline Up to 72 hours & 1 & 14.3 & 13 & 56.5 & 14 & 46.7 \\
\hline All patients & 7 & 100.0 & 23 & 100.0 & 30 & 100.0 \\
\hline
\end{tabular}


patients in group A or B with 79.0\% accuracy, better for group B (84.0\%) than for group A (60.0\%). Older patients have been reported to have more in-hospital complications, but not more reocclusions specifically, and this study did not differentiate between them.

Inferior MI have been reported in many studies ${ }^{18,20,29,30}$ as the reocclusion rates increase, and now we have found associations too probably because a high number of these associations were with the right AMI, and the right coronary artery has the greatest reocclusion rates. Those studies generated controversy about reperfusion in the the RCA or AMI, but our study showed that if the RCA is the reoccluded artery, the prognosis is very favorable.

Shorter reperfusion time (up to 240 minutes) was significant in accordance with Shirotami et al ${ }^{30}$, but we found also a later reperfusion time (up to 360 minutes) to be significant. This finding may be influenced by our small sample size.

O'Keefe et al ${ }^{15,31}$ found intimal dissecion, intraluminal thrombus, total occlusion of the culprit artery, and hemodynamic-like variables related to reocclusion, and this study showed critical lesions in place of total occlusion. Ohman et $\mathrm{al}^{6}$ in a metanalysis of reperfused patients found subtotal occlusions more frequently related to reocclusion, but this study had many patients treated with different reperfusion approaches, both isolated or associated. Vogt et al ${ }^{32}$ observed that a TIMI flow 2 postreperfusion showed an in-hospital outcome related to mortality similar to that caused by an occluded artery, but no patients in our study was considered successfully reperfused without TIMI 3 flow. Many authors have considered the geometry of lesion, residual stenosis, grade and quality flow, excentrical lesions, and residual thrombus residual to be strongly related to reocclusion phenomena ${ }^{12,15,33-44}$, the thrombus residual being the more thrombogenically ground found on laboratory testing, but our study failed in analysis of the geomety of lesions because we analyzed only the flow grade.

Higher risk patients (Killip III, Killip IV, no-class) and multivessel patients reoccluded more often and had higher mortality, probably because their clinical and hemodynamic performance did not provide them with good coronary perfusion pressure, a condition that seemed too critical to maintain artery patency and also AMI survival ${ }^{13,15,19,45-51}$. The best outcome for reperfusion is the less critical patient ${ }^{52}$.

Clinical studies ${ }^{6,8}$ have found subendocardial AMI as the main reinfarction predictor because the unstable plaque tends to close over and because its physiopathology is very different from that of the transmural AMI ${ }^{11}$, which is referred for treatment because of the major amount of viable myocardium related to the AMI culprit artery ${ }^{53,54}$.

Other studies ${ }^{55,56}$ have found early ischemia to be an MI extension predictor, which was also the main predictor of subendocarial AMI. The MILIS study ${ }^{5}$ found recurrent pain, unleveled ST segment, and early CKMB peak to be reinfarction predictors, but compounds of subendocardial reinfarction also are predictors, and when they considered a "major extension", they found also female gender. Also reported as reinfarction predictors by Morrison et al ${ }^{9}$ were obesity, female gender, and recurrent ischemia. In the pharmacological reperfusion era, the AMI can be aborted, and perhaps it will develop the physiopathology of the subendocardial infarction.

Nonreoccluded patients showed predictors that put these patients in a group with a more favorable prognosis. They had only one nonreocclusion predictor that is a predictor of mortality. Also only one CAD risk factor seems to not affect prognosis, and surprisingly it is smoking. A previous report ${ }^{57}$ has demonstrated that smokers have a more extensive thrombus component that is more susceptible to pharmacological lysis. Perhaps because anticoagulation with infused heparin was maintained in all patients in our study, it may have prevented reocclusion. On the other hand, Rivers et al ${ }^{58}$ found cigarette smoking as a reinfarction predictor at the posthospital, long- term follow-up, although patients had quit smoking.

This study did not find diabetic patients, previous CABG, or previous MI to be significant possibly because the native coronary artery in these patients was more frequently responsible for AMI, and also the circumflex artery did not show a significance as in a previous report ${ }^{15}$.

No significance existed in the number of dilated vessels in each patient. It seems to be that although multivessel lesions were a reocclusion predictor, more complete revascularization as a first approach AMI treatment did not influence final reocclusion results.

Many previous reports ${ }^{1,4,5,22,54-56}$ have shown reinfarction, AMI extension, or reocclusion as in-hospital associated with a worse prognosis, and this study showed that reocclusion is a fatal complication in $23.3 \%$ of patients compared with $1.6 \%$ of non-reoccluded patients $(\mathrm{p}=0.00004)$. Although in our series redilated patients had a better prognosis and also nonreoccluded patients had a reduction in mortality of 3.6 times compared with the global mortality of $5.8 \%$, surprisingly, Shirotami et al ${ }^{30}$ did not find any significant difference in the mortality of reoccluded patients.

Our results suggest that patients with asymptomatic reocclusion had a good prognosis, which is in accordance with previous reports ${ }^{6,59}$. Also isolated or associated angina may perhaps have the same significance as at primary AMI or perhaps it might have a preconditioning mycardial effect ${ }^{60}$. In contrast, patients who experienced shock or arrythmias at the time of reocclusion had a bad prognosis. Again, higher risk patients (clinical class, II, IV and no-class) had a higher mortality. A better class at reocclusion seems to indicate a better prognosis, but a worse class results in a patient mortality of $50.0 \%$. We have to look at this with caution, because many patients were Killip I, but many also were in more severe classes.

Although the success rates at redilation were very inferior to the initial success rates at first mechanical reperfusion and PTCA, this study suggests that redilation was the best approach, despite unsuccessful redilation, because of the intention to redilate leading to a $50.0 \%$ in-hospital reduction in mortality $(\mathrm{p}=0.0366)$. Unsuccessful redilatation indicated a poor prognosis, but when it was compared with 
not trying to redilate, no difference was found. Other studies reported benefits in open occluded arteries also, because it promotes healing of the myocardium, left aneurysm, and survival ${ }^{58,61,62}$. Also our data suggest that the impact of the nonreopened artery could be equal to or worse than the primary unsuccessful treatment ${ }^{45,47}$.

We observed also that seven mortality predictors were also reocclusion predictors, and only one was a nonreocclusion predictor. When we look at independent mortality predictors, hypertension and multivessel lesions were both reocclusion predictors, because the other variables were directly related to reocclusion and its management. Although low success rates occurred at redilatation, surviving patients had a very good NYHA class on discharge.

It has not been defined whether reocclusion is the same as reinfarction or MI extension, but this study demonstrated that reocclusion has a behavior very similar to clinical reinfaction and MI extension.

Because reocclusion is not a frequent phenomenon, despite ten years of data collection and the small number of angiographic restudies before discharge, ours is a very small sample. Also because over the years a great vertiginous advance in technological evolution, especially for "optimal stents" and the clinical use of glycoprotein inhibitors, guide wires, balloons, and new devices, reocclusion could be strongly influenced not in frequency, but perhaps in outcome ${ }^{63-74}$. This study did not analyze the CKMB curves reported in previous clinical studies, and many studies give information after 48 to 72 hours, but the majority of our patients reoccluded earlier, then we can't say whether reocclusion seems to be a reinfarction or a myocardial infarction extension based on the criteria reported in the literature.

Also no similar studies exist about the clinical significance of the in-hospital reocclusion after direct mechanical reperfusion, which is a limitation that needs discussion. Future studies could help us to better understand this phenomenon.

\section{Acknowledgements}

To Ângela da Matta Silveira Martins for statistic assistance.

\section{References}

1. Buda JA, MacDonald IL, Dubblin JD, et al. Myocardial infarct extension: prevalence, clinical significance and problem in diagnosis. Am J Heart 1983; 105: 744.

2. Kornowiski R, Goldbourt U, Zion M, et al. Predictors and long term prognostic significance of recurrent infarction in the year after a first myocardial infarction. Am J Cardiol 1993; 72: 883-8

3. Madsen BE, Gilpin E, Henning H, et al. Prediction of late mortality after myocardial infarction from variables measured at different times during hospitalization. Am J Cardiol 1984; 53: 47-54.

4. Maynard C, Weaver WD, Litwin PE and MITI Project Investigators. Hospital mortality in acute myocardial infarction in the Era of Reperfusion Therapy (The Myocardial Infarction Triage and Intervention Project). Am J Cardiol 1993; 72: 877-82.

5. Muller JE, Rude RE, BraunwaldE, et al. Myocardial infarct extension: occurrence, outcome and risk factors in the Multicenter Investigation of Limitation of Infarct Size. Ann Intern Med 1988; 108: 1-6.

6. Ohman EM, Califf RM, Topol EJ, et al. Consequences of reocclusion after successful reperfusion therapy in acute myocardial infarction. Circulation 1990; 82: 781-91

7. Stack RS, Califf RM, Hinohara R, et al. Survival and cardiac events rates in the first year after emergency coronary angioplasty for acute myocardial infarction. Journal of the Am Coll Cardiol. 1988; 11: 1141-9.

8. Marmor A, Sobel BE, Roberts E. Factors presaging early recurrent myocardial infarction (extension). Circulation 1981; 48: 603-10.

9. Marmor A, Geltman EM, Schechtman K, et al. Recurrent myocardial infarction: clinical predictors and prognostic implications. Circulation 1982; 66: 415-21.

10. Dewood MA, Spores J, Notske RN, et al. Prevalence of total coronary occlusion during the early hours of transmural myocardial infarction. N Engl J Med 1980; 303: 897-902.

11. DeWood MA, Stifter WF, Simpson CS, et al. Coronary arteriografic findings soon after non Q wave myocardial infarction. NEngl J Med 1986; 315: 417-28.

12. Gash AK, Spann JF, Sherry S, et al. Factors influencing reocclusion after coronary thrombolysis for acute myocardial infarction. Am J Cardiol 1986; 57: 175-7.

13. Rothbaum DA, Linnemeier TJ, Landn RJ, et al. Emergency percutaneous transluminal coronary angioplasty in acute myocardial infarction: a 3 years experience. J Am Coll Cardiol 1987; 10: 264-72.

14. ACC; AHA - Task force: guidelines for the early management of patients with acute myocardial infarction. J Am Coll Cardiol 1982; 16: 249-92.

15. O'Keefe JH, Rhtherford BD, McConahay DR, et al. Early and late results of coronaryplasty without antecedent thrombolytic therapy for myocardial infarction. Am J Cardiol 1989; 64: 1221-30.
16. Stack RS, O' connor CM, Mark DB, et al. Coronary perfusion during acute myocardial infarction with a combined therapy of coronary angioplasty and high dose intravenous streptokinase. Circulation 1988; 77: 151-61.

17. Topol EJ, O'Neill W, Langburd AB, et al. A randomized placebo controlled trial of intravenous recombinant tissue type plasminogen activator and emergency coronary angioplasty in patients with acute myocardial infarction. Circulation 1987; 75: 420-8.

18. Bates ER, Califf RM, Stack RS, et al. Thrombolysis and angioplasty in myocardial infarction patency, left ventricular function and mortality. J Am Coll Cardiol 1989; 13: 12-18.

19. Puel J, Rochiccioli A, Courtault $\mathrm{G}$, et al. Réoclusion précoce après désobstruction coronarienne in situ soit par streptokinase soit par angioplastie à la phase aiguë l'infarctus du myocarde. Arch Mal Coeur Vaiss 1990; 83: 175-81.

20. Simoons ML, Vos J, Tijssen JG, et al. Long term benefit of early thrombolysis therapy in patients with myocardial infarction: five years follow up of a trial conducted by the Interuniversity Cardiology Institute of Netherlands. J Am Coll Cardiol 1989; 14: 1609-15.

21. The ISAM Study Group - A prospective trial of Intravenous Streptokinase in Acute Myocardial infarction (ISAM). Mortality, morbidity and infarct size at 21 days. N Engl J Med 1986; 314: 1465-71.

22. Baker JT, Bramlet DA, Lester RM, et al. Myocardial infarct extension: incidence and relationship to survival. Circulation 1982; 65: 918-23.

23. Killip T, Kimball T. Treatment of myocardial infarction in a coronary care unit. A two year of experience with 250 patients. Am J Cardiol 1967; 20: 457-64.

24. Killip T, Kimball T. A survey of the coronary care unit: concept and results. Progr Cardiovasc Dis 1968; 11: 45-52.

25. Grüntzig A. Transluminal dilation of coronary artery stenosis. Lancet 1978; 263.

26. Mardia KV. Multivariate Analysis. New York: Academic Press Ltd., 1979.

27. Siegel S. Estatística não-paramétrica, para as ciências do comportamento. São Paulo: McGraw-Hill do Brasil, 1975.

28. Wonnacott TH, Wonnacott RJ. Estatística Aplicada à Economia e à Administração. Rio de Janeiro: Livros Técnicos e Científicos, 1981: 300-23.

29. Simoons ML, Serriuys PW, Van den Brand M, et al. Early thrombolysis in acute myocardial infarction limitation of infarct size and improved survival. J Am Coll Cardiology 1986; 7: 717-28.

30. Shirotami M, Yui Y, Hattori R, Morishita H. Emergency coronary angioplasty for acute myocardial infarction: Predictors of early occlusion of the infarcted - related artery after balloon inflation. Am Heart J 1993; 125: 931-8. 
31. O'Keefe JH Jr; Bailey WL, Rutherford BD, Hartzler GO. Primary angioplasty for acute myocardial infarction in 1000 consecutive patients. Results in na unselected population and high-risk subgroups. Am J Cardiol 1993; 72: 107G-115G.

32. Vogt A, Von Essen R, Tebbe U, et al. Impact of early reperfusion status of the infarcted related artery on short - term mortality after thrombolysis for acute myocardial infarction: retrospective analysis of four german multicenter studies. J Am Coll Cardiol 1993; 21: 1391-5.

33. Chesebro JH. The ischemic risk syndrome following thrombolysis. The problem of arterial reocclusion. Curr Opin Cardiol 1988; 3: 492-500.

34. Chesebro JH, Fuster V. Reperfusion, specific trombin inhibition and reocclusion after thrombolysis. J Am Coll Cardiol 1990; 16: 723-5.

35. Fuster V, Stein B, Badimon L, et al. Antithrombotic therapy after myocardial reperfusion in acute myocardial infarction. Am J Cardiol 1988; 12(suppl A): 78-84.

36. Fuster V, Badimon L, Cohen M, et al. Insights into the pathogenesis of acute ischemic syndromes. Circulation 1988; 77: 1213-20.

37. Fuster V. Coronary thrombolysis - a perspective for the practicing physician. $\mathrm{N}$ Engl J Med 1993; 329: 723-4.

38. Heras M, Chesebro JH, Penny WJ, et al. Importance of adequate heparin dosage in arterial angioplasty in a porcine model. Circulation 1988; 78: 654-60.

39. Meyer J, Merx W, Shmitz H, et al. Percutaneous transluminal coronary angioplasty immediately after intracoronary streptolysis of transmural myocardial infarction. Circulation 1982; 66: 905-13.

40. Wall TC, Mark DB, Califf RM, et al. Prediction of early recurrent myocardial ischemia and coronary reocclusion after successful thrombolysis: a qualitative and quantitative angiographic study. Am J Cardiol 1989; 63: 423-8.

41. Gibson CM, Cannon CP, Piana RN, et al. Angiographic predictors of reocclusion after thrombolysis: results from the thrombolysis in myocardial infarction (TIMI4). J Am Coll Cardiol 1995; 25: 582-9.

42. Chen L, Crook JR, Tousoulis D, et al. Complex stenosis morphology predicts late reocclusion during follow-up after myocardial infarction in patients with patent infarct - related coronary arteries. Am Heart J 1998; 136: 877-93.

43. Barbagelata NA, Granger CB, Oqueli E, et al. TIMI grade 3 flow and reocclusion after intravenous thrombolytic therapy: a pooled analysis. Am Heart J 1997; 133: 273-82.

44. Van'tHof AW,De BoerMJ, SuruapranataH, etal. Incidence and predictor of restenosis after successful primary coronary angioplasty for acute myocardial infarction: the importance of age and procedural results. Am Heart J 1998; 136: 518-27.

45. Bedotto JB, Kahn JK, Ruthherford BD, et al. Failed direct coronary angioplasty for acute myocardial infarction: in-hospital outcome and predictors of death. $\mathrm{J}$ Am Coll Cardiol 1993; 22: 690.

46. Harrison DG, Ferguson DW, Collins SM, et al. Rethrombosis after perfusion with streptokinase: importance of geometry of residual lesions. Circulation. 1984; 69: 991-9.

47. Kahn JK, Rutherford BD, McConahay DR, et al. Catheterization laboratory events and hospital outcome with direct angioplasty for acute myocardial infarction. Circulation 1990; 82: 1910-15.

48. Laramee LA, Rutherford BD, Ligon RW, et al. Coronary angioplasty for cardiogenic shock. Circulation 1988; 78(suppl II): 634.

49. Lee L, Bates ER, Pitt B, et al. Percutaneous transluminal coronary angioplasty improves survival in acute myocardial infarction complicated by cardiogenic shoch. Circulation 1988; 78: 1345-51.

50. Maroko P, Kjekshus JK, Sobel BE, et al. Factors influencing infarct size following experimental coronary occlusions. Circulation 1971; 67-82.

51. Meade TW. Low dosis warfarin and low dosis aspirin in the primary prevention of ischemic heart disease. J Am Coll Cardiol 1990; 65(suppl C): 7-11.

52. Brodie BR, Weintraub RA, Stuckey TD, et al. Outcomes of direct coronary angioplasty for acute myocardial infarction in candidates and non candidates for thrombolytic therapy. Am J Cardiol 1991; 67: 7-12.
53. Gibson RS, Beller GA, Gheorghiade M, et al. The prevalence and clinical significance of residual myocardial ischemia 2 weeks after uncomplicated non Q wave infarction: a prospective natural history study. Circulation 1986; 73 : 1186-98.

54. Gibson RS, Boden WE, Theroux P, et al. Diltiazem and reinfarction in patients with non Q wave myocardial infarction. Results of a double-blind, randomized Multicenter Trial. N Engl J Med 1986; 315: 423-9.

55. Bosch X, Theroux P, Waters DD, et al. Early post infarction ischemia: clinical, angiografic and prognosis significance. Circulation 1987; 75: 988-95.

56. Maisel AS, Ahnve S, GilpinE, et al. Prognosis after extension of myocardial infarct: the role of Q wave or non Q wave infarction. Circulation 1985; 71: 211-17.

57. Gomes MA, Karagounis LA, Allen A, et al. Effect of cigarrette smoking on coronary patency after thrombolytic for myocardial infarction. Am J Cardiol 1993; 72: 373-7.

58. Rivers JT, White HD, Cross DB, et al. Reinfarction after thrombolytic terapy for acute myocardial infarction followed by conservative management: incidence and effect of smoking. J Am Coll Cardiol 1990; 16:340-8.

59. ISIS-2 - Second International Study of Infarct Survival. Collaborative Group. Randomized trial of intravenous streptokinase, oral aspirin, both, or neither among 17.187 cases of suspected acute myocardial infarction. ISIS-2. Lancet 1988; 2: 349-69.

60. O'Neill W. Reperfusion therapy of myocardial infarction. Progr Cardiovasc Dis 1988; 30: 235-64.

61. Braunwald E. Thrombolytic reperfusion of acute myocardial infarction: resolved and unresolved issues. J Am Coll Cardiol 1988; 12(suppl A): 85-92.

62. Kennedy JW, Western W. Randomized Trial of intracoronary streptokinase in acute myocardial infarction. N Engl J Med 1985; 312: 1073-7.

63. Spaulding C, Cador R, Benhamda K, et al. One-week and six-month angiographic controls of stent implantation after occlusive and nonocclusive dissection during primary balloon angioplasty for acute myocardial infarction. Am J Cardiol 1997; 79: 1592-5.

64. Neumann FJ, Walter H, Richardt G, et al. Coronary Palmaz-Schatz stent implantation in acute myocardial infarction. Heart 1996; 75: 121-6.

65. Mehta RH, Bates ER. Coronary stent implantation in acute myocardial infarction. Am Heart J 1999; 137: 603-11.

66. Gersh BJ. Current issues in reperfusion therapy. Am J Cardiol 1998; 82(8B): 3-11

67. Morice MC, Lefevre T, Louvard Y, et al. Stenting in acute myocardial infarction. Semin Interv Cardiol 1998; 3: 77-80.

68. Grines CL. Agressive intervention for myocardial infarction: angioplasty, stents and intra-aortic balloon pumping. Am J Cardiol 1996; 78(3A): 29-34.

69. Verheugt FW, Meijer A, Lagrand WK, et al. Reocclusion: the flip side of coronary thrombolysis. J Am Coll Cardiol 1996; 27: 766-73.

70. Montalescot G. IIb IIIa inhibitors in acute myocardial infarction. Blood Coagul Fibrinolysis (England) 1999; 10(suppl 1): 71-5.

71. Gersh BJ. Optimal management of acute myocardial infarction at the dawn of the next millennium. Am Heart J 1999; 138: 188-202.

72. Nakagawa Y, Iwasaki Y, Kimura T, et al. Serial angiographic follow-up after successful direct angioplasty for acute myocardial infarction. Am J Cardiol 1996; 78: $980-4$.

73. Stone GW, Marsalese D, Brodie BR, et al. A prospective randomized evaluation of prophylactic intraaortic balloon counterpulsation in high risk patients with acute myocardial infarction treated with primary angioplasty. Second primary angioplasty in myocardial infarction (PAMI I-II) trial investigators. J Am Coll Cardiol 1997; 29: 459-67.

74. White HD, French JK, Hamer AW, et al. Frequent reocclusion of patient infarct related arteries between 4 weeks and 1 year: effects of antiplatelet therapy. J Am Coll Cardiol 1995; 25: 218-23. 